\title{
A Case of Successful Colonoscopic Treatment of Acute Appendiceal Bleeding by Endoclips
}

\author{
Il Hyung Chung, Kwang Hyun Kim \\ Department of Internal Medicine, Onnuri Hospital, Ansan, Korea
}

Lower gastrointestinal bleeding is a common disease among elderly patients. The common sources of lower gastrointestinal bleeding include vascular disease, Crohn's disease, neoplasm, inflammatory bowel disease, hemorrhoid, and ischemic colitis. However, bleeding from the appendix has been reported very rarely in patients with lower gastrointestinal tract bleeding. In general, after a colonoscopic diagnosis of appendiceal bleeding, a laparoscopic or surgical appendectomy would be recommended. We report a case of successful colonoscopic treatment of appendiceal bleeding without complications by endoclips. This report suggests that colonoscopic clipping is a safe and effective means to treat bleeding from appendiceal lesions. Further study is needed to evaluate procedure-related complications and to confirm the procedure's safety and efficacy.

Keywords: Appendix; Bleeding; Colonoscopy; Clip

\section{INTRODUCTION}

The most common causes of lower gastrointestinal bleeding are known to be vascular disease, intestinal neoplasm, inflammatory bowel disease, ischemic colitis and hemorrhoid $[1,2]$, and appendiceal bleeding is known to be an extremely rare cause [3]. The reported causative factors of appendiceal bleeding to date are angiodysplasia, appendicitis, diverticulum, endometriosis, intussusception, carcinoid, lymphoma, and Crohn's disease [4-11]. The appendectomy is commonly known to be the most effective treatment for appendiceal bleeding [5], but the authors successfully performed endoscopic clipping without any complications in patient with acute massive lower gastrointestinal bleeding caused by appendiceal bleeding and report this case with a literature review.

Received: July 25, 2011 Accepted: August 27, 2011

Correspondence to: II Hyung Chung, M.D.

Department of Internal Medicine, Onnuri Hospital, 1087-28 Seonbu-dong,

Danwon-gu, Ansan 425-831, Korea

Tel: +82-31-412-2230, Fax: +82-31-475-2375

E-mail:wemster@hanmail.net

(c) 2011 The Korean Society of Coloproctology

This is an open-access article distributed under the terms of the Creative Commons Attribution NonCommercial License (http://creativecommons.org/licenses/by-nc/3.0) which permits unrestricted noncommercial use, distribution, and reproduction in any medium, provided the original work is properly cited.

\section{CASE REPORT}

A 70-year-old man was admitted to our hospital complaining of hematochezia that had developed 2 days earlier. He had no history of smoking or alcohol intake. He had been diagnosed with hypertension 5 years earlier at a private clinic and was taking antihypertensive medications, but had never taken anti-platelets such as aspirin. His blood pressure was $90 / 60 \mathrm{mmHg}$, his heart rate was 110 beats/minute, his respiration rate was 24 breaths/minute, and his body temperature was $36.7^{\circ} \mathrm{C}$ when he was admitted to our hospital. The lung sound and the heart sound were within normal limits, but the bowel sound was increased on auscultation. The abdomen was soft, and the liver and the spleen were not palpable on physical examination. The leukocyte count was $12,500 / \mathrm{mm}^{3}$, hemoglobin was $10.5 \mathrm{~g} / \mathrm{dL}$, and the platelet count was $234,000 / \mathrm{mm}^{3}$ on the blood test. Electrolyte, biochemistry, and urine analysis were within normal limits. There were no abnormal findings on the chest $\mathrm{X}$-ray, and there were no specific abnormalities on the abdominal $\mathrm{X}$-ray either.

Suspecting acute lower gastrointestinal bleeding, we performed emergency endoscopy and sigmoidoscopy. There was no evidence of upper gastrointestinal bleeding on endoscopy, but there was a large amount of fresh blood from the rectum to the sigmoid colon on sigmoidoscopy (Fig. 1). However, the bleeding source was not identified because it was difficult to secure a clear visual field and to 
advance due to feces. Consequently, colonoscopy was performed after bowel preparation and blood transfusion. The colonoscopy was done up to the terminal ileum, and active bleeding from the appendix was observed (Fig. 2). Endoscopic hemostasis was attempted using a clip (EZ clip; Olympus, Tokyo, Japan), and the procedure was completed after clipping twice and confirming successful hemostasis (Figs. 3, 4). The computed tomography (CT)



Fig. 1. Sigmoidoscopic finding. Fresh blood was observed in the sigmoid colon.

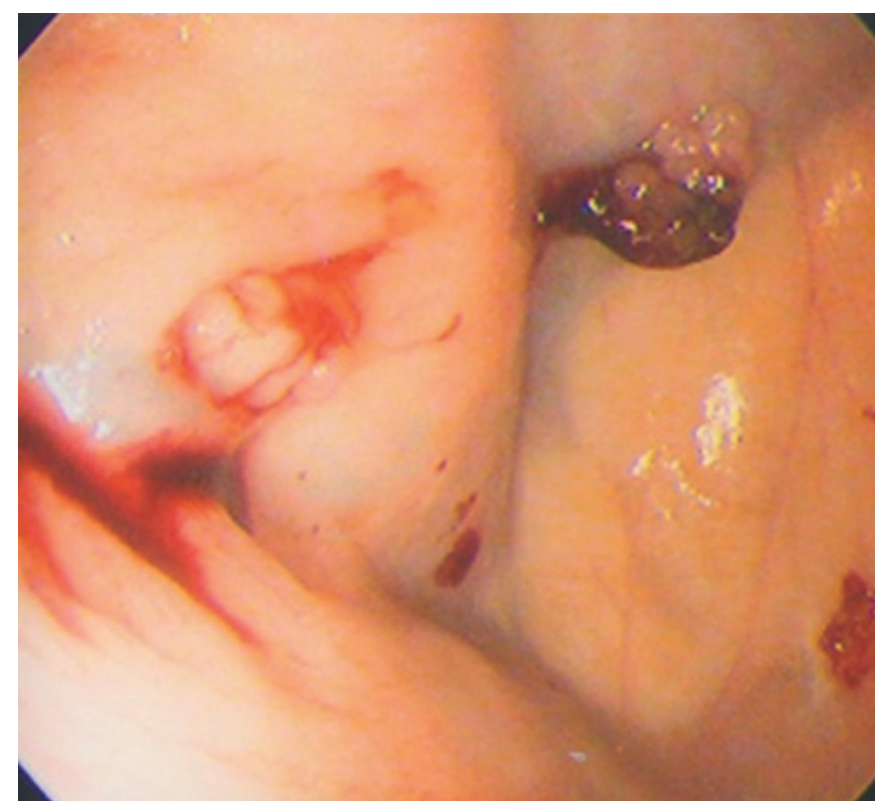

Fig. 2. Colonoscopic finding. Active bleeding from the appendiceal orifice was noted. scan showed no evidence of acute appendicitis or any other specific lesion around the appendix (Fig. 5). The blood test showed no reduced hemoglobin, and his blood pressure and hematochezia were improved. A follow-up colonoscopy was performed after 3 days, evidence of neither further bleeding nor post-procedural appendicitis were found, so the patient was discharged.

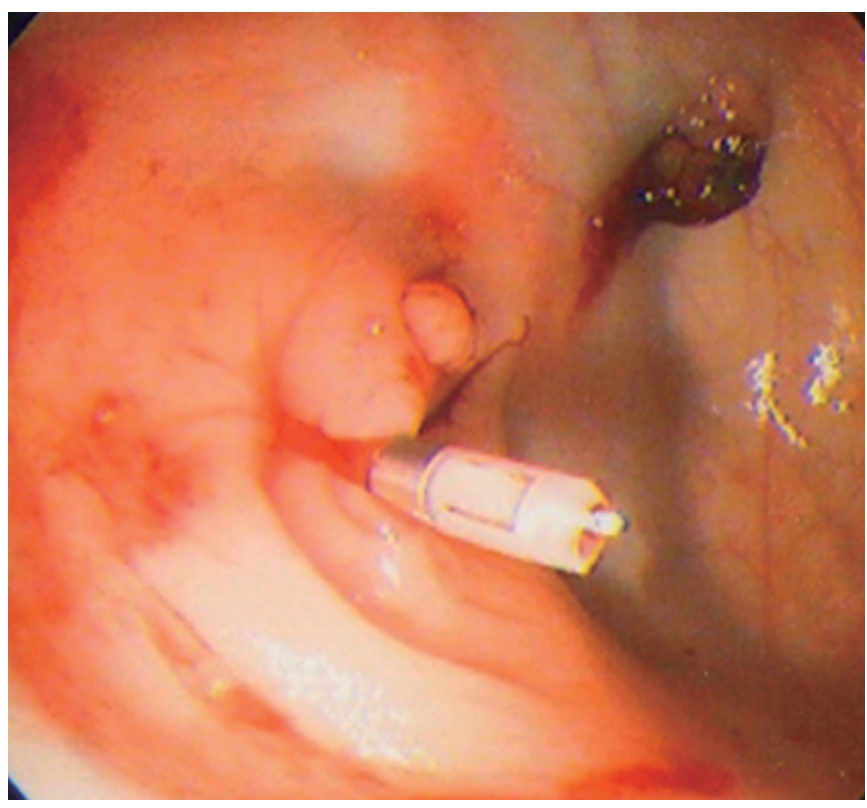

Fig. 3. First colonoscopic clipping. Note the partial occlusion of the appendiceal orifice to prevent post-procedural appendicitis.

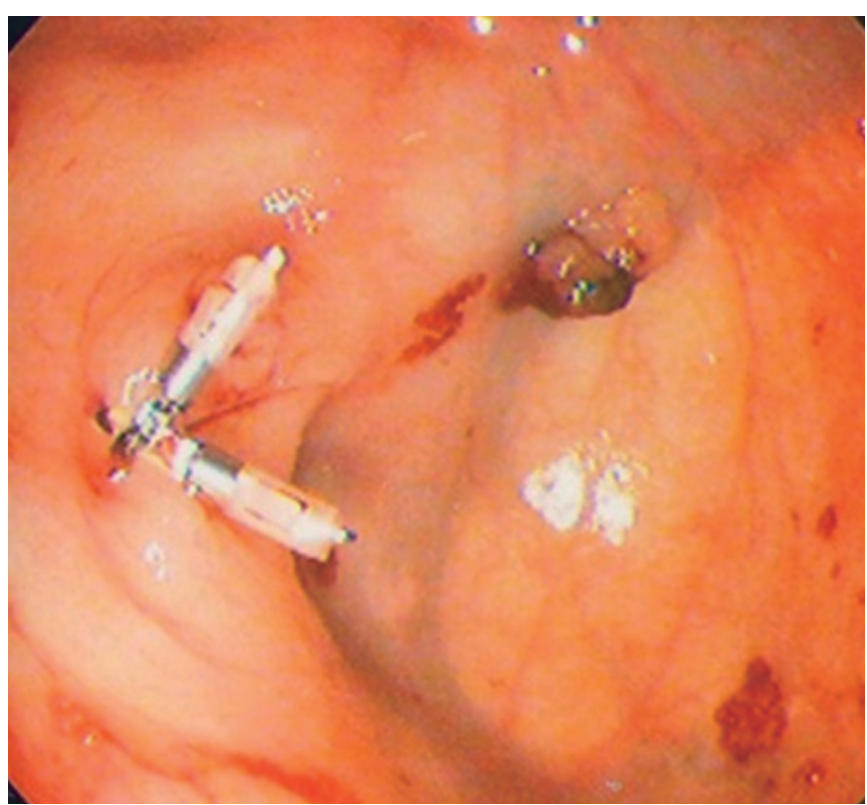

Fig. 4. Second colonoscopic clipping. No blee- ding was observed after the second additional clipping. 


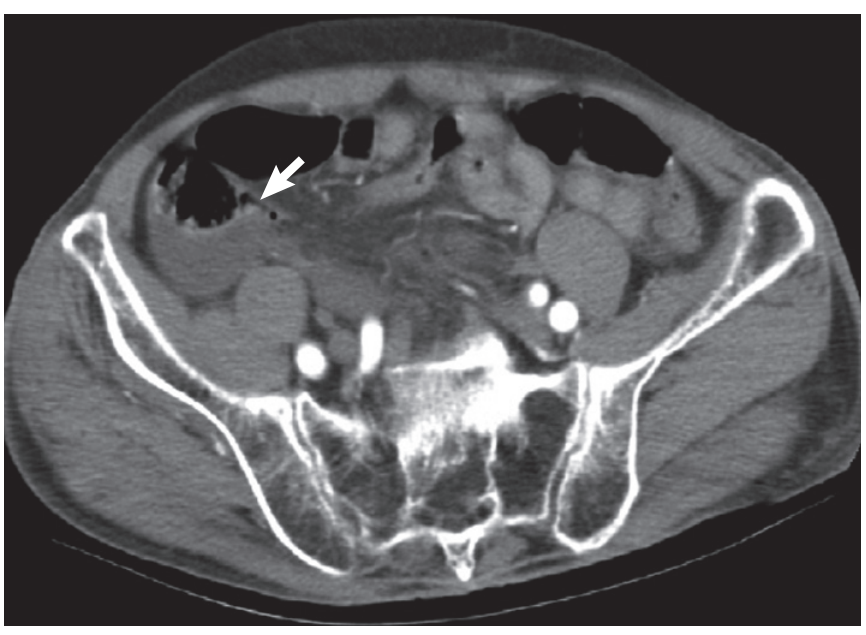

Fig. 5. Computed tomography (CT) finding. Abdominal CT scan showed a normal-looking appendix (arrow).

\section{DISCUSSION}

The prevalence of lower gastrointestinal bleeding is known to be about $0.02 \%$ and it is higher in men and elderly populations [12]. The common causative factors are vascular disease, intestinal neoplasm, inflammatory bowel disease, ischemic colitis, and hemorrhoid $[1,2]$.

Appendiceal bleeding is known to be a rare cause of lower gastrointestinal bleeding [3], and it can be caused by angiodysplasia, mucosal erosion associated with acute appendicitis, appendiceal diverticulum, appendiceal endometriosis, intussusception of the appendix, carcinoid, lymphoma, and Crohn's disease [4-11]. Generally, submucosal vessels are exposed when appendicitis occurs in these diseases described above, and this can cause bleeding. Baek et al. [13] reported that appendiceal bleeding should be differentiated from Crohn's disease, mucocele, diverticulum, fistula connected to the aorta, endometriosis, angiodysplasia, dilation of submucosal vessels, granuloma, intussusception, ulcer secondary to aspirin, and gastrointestinal stromal tumor.

The appendectomy is the most common treatment for appendiceal bleeding [5], but percutaneous tanscatheter arterial embolization is known to be useful for appendiceal bleeding caused by angiodysplasia [4], and successful cases have been reported nationally. However, percutaneous transcatheter arterial embolization should be attempted selectively when primary endoscopic hemostasis has failed because it can cause complications such as necrosis of normal mucosa and perforation.

The authors successfully performed endoscopic clipping without any complications in a patient with acute appendiceal bleeding after confirming that there was no evidence of acute appendicitis or other specific lesions around appendix on abdominal CT and colonoscopy. This report is unique because endoscopic clipping was attempted initially instead of an appendectomy and the procedure was successfully completed without complication whereas the appendectomy is known to be the most common treatment for appendiceal bleeding based on a review of the literature to date. In other words, there have been a number of case reports regarding the causes of appendiceal bleeding, but none of them reported successful endoscopic clipping to treat appendiceal bleeding. Therefore, this report is significant in that it suggests to skillful endoscopy specialists a new therapeutic strategy that enables them to manage appendiceal bleeding swiftly by using endoscopic clipping, which is both simple and safe.

The appendiceal bleeding in our patient was thought to be caused by angiodysplasia because the patient did not have any history of aspirin therapy. Endoscopic clipping is judged to be a safe and effective therapeutic method before considering surgery when there are no other specific findings except appendiceal bleeding on abdominal CT and colonoscopy.

The authors attempted to ligate by locating one wing of the clip towards the inside of the appendix opening and the other wing towards the outside after predicting the direction where the blood might leak, instead of ligating the opening completely, to prevent post-procedural appendicitis (Fig. 3). This ligation method was thought to prevent post-procedural appendicitis, as well as provide effective hemostasis.

There is a total lack of evidence regarding endoscopic clipping related to appendiceal bleeding internationally because appendiceal bleeding is a rare disease and because in the literature, surgery is described as the most effective therapeutic method, but much evidence exists in the literature describing endoscopic clipping as an effective therapeutic method for diverticular bleeding [14, 15]. Therefore, further research regarding its safety and complication associated with the procedure should be conducted in the future.

\section{CONFLICT OF INTEREST}

No potential conflict of interest relevant to this article was reported.

\section{REFERENCES}

1. Weldon DT, Burke SJ, Sun S, Mimura H, Golzarian J. Interventional management of lower gastrointestinal bleeding. Eur Radiol 2008; 18:857-67.

2. Edelman DA, Sugawa C. Lower gastrointestinal bleeding: a review. Surg Endosc 2007;21:514-20.

3. Strate LL. Lower GI bleeding: epidemiology and diagnosis. Gastroenterol Clin North Am 2005;34:643-64.

4. Kyokane T, Akita Y, Katayama M, Kitagawa Y, Sato T, Shichino S, et al. Angiodysplasia of the appendix. Am J Gastroenterol 2001;96: 242-4.

5. Yamazaki K, Nakao K, Tsunoda A, Ohnaka T, Amagasa H, Suzuki $\mathrm{N}$, et al. Successful laparoscopic treatment of hemorrhage from the appendix with phlegmonous acute appendicitis: a case report and review of the literature. Gastrointest Endosc 2006;63:877-80. 
6. Norman DA, Morrison EB, Meyers WM Jr. Massive gastrointestinal hemorrhage from a diverticulum of the appendix. Dig Dis Sci 1980;25:145-7.

7. Shome GP, Nagaraju M, Munis A, Wiese D. Appendiceal endometriosis presenting as massive lower intestinal hemorrhage. Am J Gastroenterol 1995;90:1881-3.

8. Brewer RJ, Wangensteen SL. Appendiceal intussusception: an unusual cause of painless rectal bleeding. Am Surg 1974;40:319-20.

9. Chen YY, Soon MS. Carcinoid tumor of the appendix. Gastrointest Endosc 2000;51:465.

10. Carpenter BW. Lymphoma of the appendix. Gastrointest Radiol 1991;16:256-8.

11. Brown WK, Peters RW. Crohn's disease of the appendix present- ing as lower intestinal hemorrhage and cecal mass. Am J Gastroenterol 1976;65:349-52.

12. Chiang CC, Tu CW, Liao CS, Shieh MC, Sung TC. Appendiceal hemorrhage: an uncommon cause of lower gastrointestinal bleeding. J Chin Med Assoc 2011;74:277-9.

13. Baek SK, Kim YH, Kim SP. Acute lower gastrointestinal bleeding due to appendiceal mucosal erosion. Surg Laparosc Endosc Percutan Tech 2010;20:e110-3.

14. Yen EF, Ladabaum U, Muthusamy VR, Cello JP, McQuaid KR, Shah JN. Colonoscopic treatment of acute diverticular hemorrhage using endoclips. Dig Dis Sci 2008;53:2480-5.

15. Pilichos $C$, Bobotis $E$. Role of endoscopy in the management of acute diverticular bleeding. World J Gastroenterol 2008;14:1981-3. 